\title{
INFECÇÃO EM CIRURGIA
}

\author{
INFECTION IN SURGERY
}

Aldo Cunha Medeiros, Marília Daniela Ferreira de Carvalho

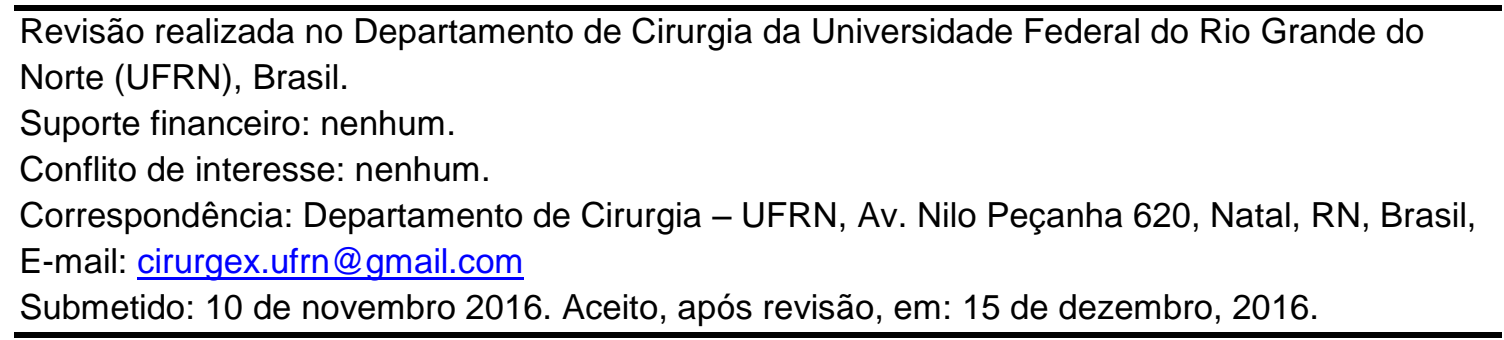

\begin{abstract}
Background/ Purpose: This review aimed to discuss developments in care and surgical approaches to prevent, diagnose and treating surgical site infection, together with antimicrobial treatments, in order to significantly reduce the morbidity and mortality rates associated with this injury. Methods: Review of the pertinent English and Portuguese-language literature using electronic data bases. Results: Several resistant organisms have emerged as the maleficent cause of invasive infection in surgical patients. We discussed risk for surgical site infection as multifactorial and included a host of microbial, patient-related, and procedure-related factors. Prevention of surgical infection relies on optimization of patient factors and use of a variety of pharmacologic and non-pharmacologic measures were analysed. Surveillance and antibiotic prophylaxis has been shown to be effective at reducing risk of surgical site infection. Conclusion: It is important to recognize infection, and stablish measures for prevention of surgical site infection. This is an increasingly complex and nuanced problem. Strict infection control measures, and constant surveillance remain the principal adjuncts to control of invasive infections in surgical patients.
\end{abstract}

Key words: Infection. Surgery; Surgical site infection; Prophylaxis. Antibiotics.

\section{RESUMO}

Objetivo: Este trabalho de revisão teve como objetivo discutir conceitos, fatores de risco e abordagens cirúrgicas para prevenir, diagnosticar e tratar a infecção do sítio cirúrgico, juntamente com tratamentos antimicrobianos, a fim de reduzir significativamente as taxas de morbidade e mortalidade associadas à infecção. Métodos: Revisão da literatura pertinente em inglês e português utilizando bases de dados eletrônicas. Resultados: Vários organismos resistentes emergiram como a causa maléfica de infecção invasiva em pacientes cirúrgicos. Discutimos o risco de infecção do sítio cirúrgico como multifatorial e incluímos uma série de fatores 
microbianos, relacionados ao paciente e relacionados ao procedimento. A prevenção da infecção cirúrgica baseia-se na otimização dos fatores do paciente e o uso de umavariedade de medidas farmacológicas e não-farmacológicas foram analisadas. $O$ conceito de profilaxia antimicrobiana demonstram ser eficazes na redução do risco de infecção em paciente cirúrgico. Conclusão: É importante reconhecer a infecção e estabelecer medidas para a prevenção da infecção do sítio cirúrgico. Este é um problema cada vez mais complexo e repleto de nuances. As medidas de controle de infecção e a vigilância constante das feridas continuam a ser os principais adjuntos ao controle de infecções invasivas em pacientes cirúrgicos.

Descritores: Infecção. Cirurgia; Infecção do local cirúrgico; Profilaxia. Antibióticos.

\section{INTRODUÇÃO}

A infecção pós-operatória é determinada por uma combinação de fatores: quantidade e tipo de contaminação, técnica cirúrgica e anestésica empregada e resistência do hospedeiro. A infecção hospitalar é um processo infeccioso decorrente de microorganismo presente no ambiente hospitalar. Corresponde acerca de $10 \%$ de todas as internações hospitalares. Próximo de $30 \%$ das infecções hospitalares são evitáveis com medidas preventivas. As principais infecções hospitalares são as urinárias, as respiratórias, as da ferida cirúrgica e a septicemia, enquanto que as principais infecções cirúrgicas (pósoperatórias) são as do próprio local cirúrgico, as urinárias e as respiratórias. As infecções pós-operatórias, que habitualmente são do local cirúrgico, têm alta morbi-mortalidade e tempo de permanência hospitalar prolongado ${ }^{1,2}$.

- $70 \%$ das infecções hospitalares ocorrem em casos cirúrgicos

- $30 \%$ em casos clínicos

- Custos anuais diretos e indiretos:

- Aproximadamente um bilhão de dólares (USA)

- PROBleMa social PREOCUPANTE

\section{RESPOSTA À INFECÇÃO}

A resposta orgânica à infecção depende: 1- Da virulência e do número de microorganismos infectantes; 2- Do meio em que a infecção se 
desenvolverá; 3- Dos mecanismos de defesa do hospedeiro (barreiras à infecção): - Mecânicas (paredes que separam o agente dos tecidos estéreis); Humorais (IgG, $\lg M$ e $\lg A$ ); - Celulares (macrófagos e neutrófilos); - Citocinas (liberadas pelos macrófagos); 4- Presença de fatores que levam à imunossupressão: paciente idoso, diabetes, desnutrição, leucopenia, corticoterapia, radio e quimioterapia ${ }^{2}$.

\section{PREVENÇÃO}

Há várias recomendações para a prevenção das infecções pósoperatórias: No pré-operatório - Preparo do paciente e hospitalização préoperatória de curta duração; - Lavagem das mãos e antebraços da equipe cirúrgica; - Controle de pessoal contaminado ou infectado no ambiente hospitalar; - Esterilização do material cirúrgico; - Profilaxia antimicrobiana; Cuidados de antissepsia e técnica adequada na instalação de catéter venoso central ${ }^{3-5}$.

A cirurgia e o controle clínico do paciente cirúrgico têm apresentado nos últimos anos avanços importantes que refletiram diretamente em uma queda nas taxas de morbi-mortalidade de pacientes submetidos a procedimentos cirúrgicos. Contudo, a infecção pós-operatória ainda representa uma complicação importante, cobrando um elevado tributo em mortalidade, morbidade e custo direto, indireto e intangível ao tratamento médico do paciente. A infecção é uma complicação inerente ao ato cirúrgico e se faz necessário um grande esforço para mantê-la sob controle e em níveis aceitáveis, dentro dos padrões das instituições hospitalares, de tal modo que a análise de seus índices constitui, hoje, um parâmetro de controle de qualidade do serviço prestado por um hospital 6 .

- Estima-se que o custo do tratamento da infecção da ferida cirúrgica nos Hospitais Brasileiros é em média de $R \$ 3.500,00$ por paciente.

- INFECÇÃO HOSPITALAR:

- $10 \%$ das internações

- Aumento da internação em 4 a 26 dias (média 15 dias)

- Aumento exorbitante do custo por paciente ${ }^{4,6}$ 
Comparando com os anos 60 e 70, atualmente na área de cirurgia passou a predominar uma clientela de pacientes idosos, imunodeprimidos, portadores de neoplasias e em uso de quimio e radioterapia, pacientes transplantados em uso de drogas imunossupressoras, pacientes de alto risco de infecção, nos quais são utilizados procedimentos cada vez mais invasivos no diagnóstico e na terapêutica, além da utilização de antimicrobianos de espectro mais amplo, fazendo surgir bactérias mais resistentes e agressivas. Quando ocorre infecção pós-operatória, a repercussão negativa é inevitável6:

Se estes fatos ocorreram com o paciente cirúrgico, importantes e significativas mudanças têm ocorrido com os agentes etiológicos. As bactérias Gram-negativas (E. coli, Klebisiella), responsáveis até então pelas infecções pós-cirúrgicas, estão dando lugar à bactérias Gram-positivas, Pseudomonas e Cândida, assim como, a um aumento considerável dos níveis de resistência dessas bactérias a antibióticos rotineiramente usados na clínica cirúrgica ${ }^{3}$.

- Infecção pós-operatória:

- Grande aumento dos riscos e morbi-mortalidade

- Aumento da permanência hospitalar

- Aumento dos custos

- Infecção hospitalar: Processo infeccioso causado por microrganismo adquirido dentro do ambiente hospitalar

O aumento da resistência bacteriana nos Estados Unidos tem provocado um custo anual estimado em 100-300 milhões de dólares. O nível de resistência está diretamente relacionado à quantidade e ao modo de utilização do antibiótico naquele ambiente ${ }^{4}$. Além dessas mudanças de perfil no paciente cirúrgico e no agente agressor, os hospitais têm sofrido importantes modificações. Hospitais de alta complexidade passaram a se comportar como centros de referência, recebendo predominantemente este tipo de paciente e albergando microrganismos selecionados de alta virulência ${ }^{3,7,8}$.

\section{Ao cirurgião compete:}

- A responsabilidade de lidar com infecções 
- Conhecer e usar técnicas assépticas e antissépticas

- Usar corretamente antibiótico terapêutico e profilático

- Usar racionalmente e com senso crítico as inovações tecnológicas

- Conhecer os mecanismos de defesa às infecções

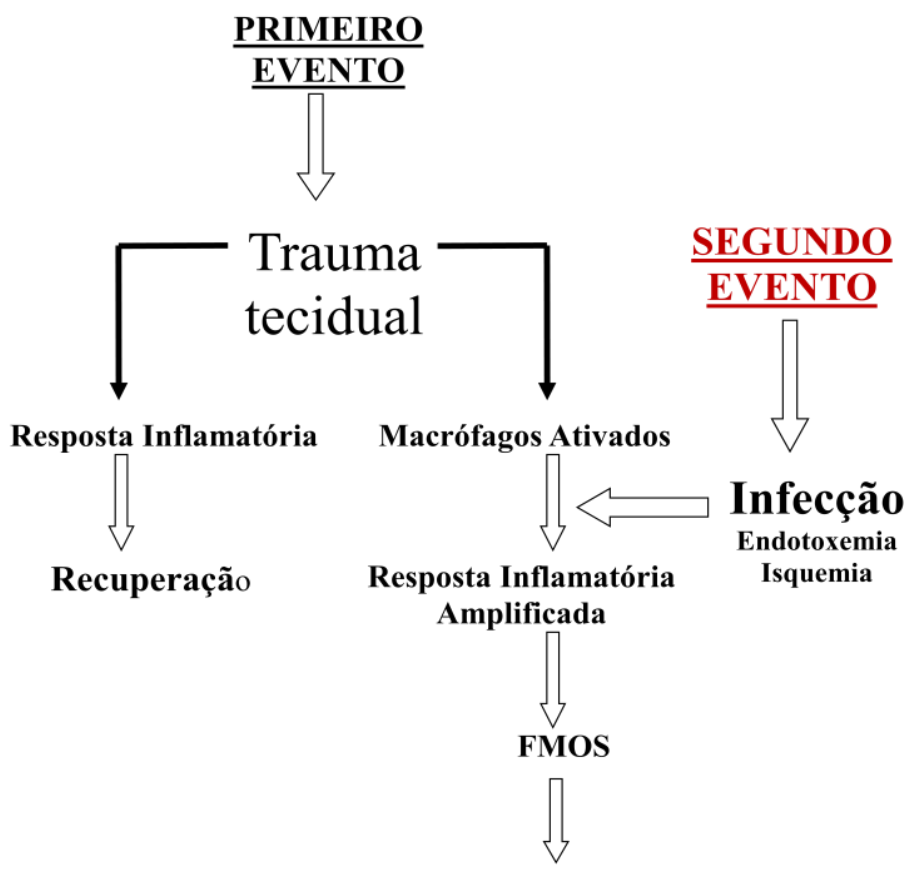

MORTE

Figura 1 - Esquema da evolução de um paciente que é operado e é acometido de infecção pós-operatória, agravando enormemente seu estado.

\section{PREVENÇÃO E CONTROLE}

Há várias recomendações para a prevenção das infecções pós-operatórias: No pré-operatório - Preparo do paciente e hospitalização pré-operatória de curta duração; - Lavagem das mãos e antebraços da equipe cirúrgica; - Controle de pessoal contaminado ou infectado no ambiente hospitalar; - Esterilização do material cirúrgico;

- Profilaxia antimicrobiana; - Cuidados de antissepsia e técnica adequada na instalação de catéter venoso central ${ }^{7,8,10}$. Várias medidas têm sido propostas para reduzir e controlar o problema da infecção cirúrgica, mas é evidente que o principal fator que poderá interferir com este problema é a educação da comunidade hospitalar.

No Brasil o grande interesse pelo tema infecção hospitalar teve início em 1985, quando ocorreu a morte de um Presidente da República eleito, operado de urgência na véspera de sua posse, e que faleceu vítima de infecção hospitalar ${ }^{6}$. 


\section{Interesse pelo tema}

- Crescente público bem informado

- Riscos de cobranças judiciais

- No Brasil: 21/4/1985 - Morte de presidente da República eleito (Tancredo Neves) por infecção hospitalar, na véspera de sua posse

- Criação e valorização de Comissões de Controle de Infecção Hospitalar $(\mathrm{CClH})$ nos hospitais a partir desta data

\section{A COMISSÃO DE CONTROLE DE INFECÇÃO HOSPITALAR (CCIH)}

Órgão encarregado de informar, vigiar, pesquisar, prevenir e controlar as infecções hospitalares. O objetivo principal de um programa de controle de infecção é exercer uma ação educativa na comunidade hospitalar quanto à importância da prevenção e controle das infecções e, assim, reduzir o nível de infecção hospitalar endêmica e epidêmica ${ }^{9}$.

A $\mathrm{CCIH}$ realiza reuniões mensais e em geral emite relatórios trimestrais destinados aos serviços dos hospitais. São divulgadas nestes relatórios taxas específicas relacionando infecção de ferida em cirurgia limpa e eventualmente os cirurgiões responsáveis pelos infectados ${ }^{10}$.

\section{CLASSIFICAÇÃO DAS FERIDAS CIRÚRGICAS}

As intervenções cirúrgicas são classificadas segundo o risco de contaminação ${ }^{2,3} \mathrm{em}$ limpa, potencialmente contaminada, contaminada e infectada, de acordo com recomendações dos Colégios Americano e Brasileiro de Cirurgiões ${ }^{6}$, e assim definidas:

- Limpas: são as de reduzido potencial de infecção. Não ocorre abertura de vísceras ocas ou infração da técnica asséptica. Ex: tireoidectomia

- Potencialmente contaminadas: ocorre abertura de víscera oca, com mínimo de extravasamento de conteúdo ou pequenas infrações técnicas. Ex: colecistectomia

- Contaminadas: abertura de víscera oca com grosseiro extravasamento de conteúdo, inflamação aguda sem pus, infrações grosseiras 
na técnica asséptica e lesões traumáticas com menos de seis horas. Ex: Colectomia, apendicectomia.

- Infectadas: presença de pus, víscera oca perfurada e lesões traumáticas com mais de seis horas de evolução ${ }^{12,13}$. Ex: Cirurgia da diverticulite perfurada.

Quando da admissão, os pacientes devem ser examinados e orientados no que se refere ao banho com lavagem da cabeça e do local da cirurgia, tricotomia 1-2 horas antes da intervenção e quando indicado, preparo mecânico dos cólons. A identificação de infecção comunitária associada à afecção cirúrgica determina a suspensão do procedimento eletivo e o paciente tem o tratamento desta infecção instituído ${ }^{6}$.

Os pacientes durante o período pós-operatório, quando internados, devem ser visitados por um ou mais técnicos da $\mathrm{CCIH}$, que em um sistema de busca ativa, quando é verificado o estado da ferida operatória, o uso de antimicrobianos, curva térmica, queixas urinárias e respiratórias, além de infecções associadas. Por ocasião da alta o paciente deve ser orientado a retornar ao Ambulatório de Egressos da Unidade de Clínica Cirúrgica, que centraliza o retorno de todos os pacientes cirúrgicos do hospital. Nesta ocasião, supervisiona-se o estado da ferida, com realização de curativos, retirada dos pontos cirúrgicos, investigação de queixas urinárias e respiratórias. O retorno ao ambulatório deve-se dar em torno do $15^{\circ}$ ao $30^{\circ}$ dia de pós-operatório ${ }^{6,13}$.

\section{IDENTIFICAÇÃO DAS INFECÇÕES CIRÚRGICAS MAIS FREQUENTES}

A presença de pus é o critério utilizado para classificar a ferida como infectada. O diagnóstico da infecção respiratória é eminentemente clínico (tosse produtiva, alterações radiológicas e febre). O diagnóstico da infecção urinária baseiase inicialmente na sintomatologia característica com disúria, febre e calafrios e no resultado da urocultura. Uroculturas com mais de 100.000 colônias $/ \mathrm{ml}$ são consideradas positivas. Pacientes com um número de colônias bacterianas menor, mas com sintomatologia urinária, também são considerados como positivos. As CCIHs tem divulgado uma política de indicação restrita de cateterismo urinário, com padronização de técnica asséptica e utilização de sistema de drenagem fechado. Nos casos de pacientes em pré-operatório imediato, com indicação de cateterismo urinário, 
a colocação do cateter deve ser feita na sala de cirurgia, com o paciente anestesiado e todos os cuidados de assepsia ${ }^{6,10}$.

\section{INFECÇÃO DA FERIDA OPERATÓRIA}

É a mais frequente nos operados. O tempo de internamento aumenta em média 7 a 8 dias por paciente; O custo adicional tem sido de 840 dólares/paciente; geralmente ocorre ou é detectada após a alta hospitalar; tornando necessário o ambulatório de controle pós-operatório ${ }^{6,9,10}$.

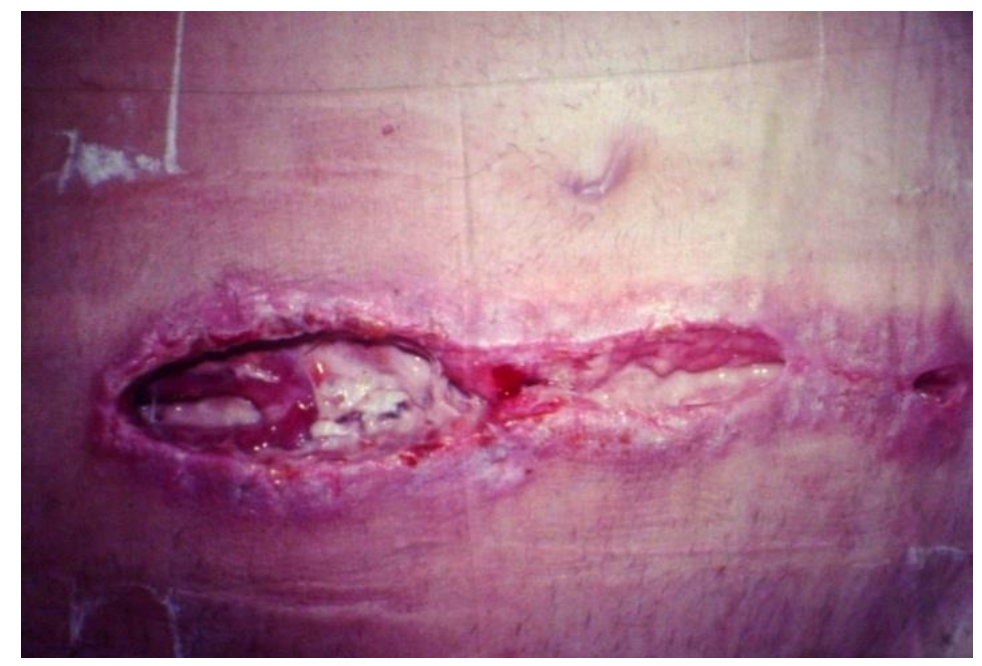

Figura 2 - Ferida operatório infectada em paciente diabético.

\section{Fatores etiológicos da infecção da ferida}

- Ausência de lavagem das mãos do cirurgião

- Ausência de lavagem das mãos da equipe de apoio

- Enfermagem, residentes, estudantes, etc ${ }^{7,15}$.

- A pele do paciente

- Hospitalização pré-operatória prolongada

- Duração da operação

- Técnica operatória

Tratamento da infecção da ferida operatória é essencialmente local

- Retirar os pontos

- Debridar tecidos necróticos 
- Opcionalmente usar soluções para limpeza, como a solução salina $0,9 \%$. Alguns serviços têm usado permanganato 1:10.000, açúcar, mel de abelha, óleo de girassol, etc.

- Antibiótico sistêmico só em casos de sepse e infecções à distância (urinária, respiratória, etc), diabetes e debilidade orgânica.

\section{Infecção Urinária}

- $2^{\mathrm{a}}$ infecção pós-operatória mais freqüente;

- > 100.000 colônias de bactérias/ml de urina;

- Disúria, febre e calafrios.

- Estreita relação com sondas vesicais: 40 a 50\% após 10 dias de uso da sonda

- Coletores urinários abertos: Prevalência de infecção: $95 \%{ }^{9}$

\section{Infecção Respiratória}

- $\quad 3^{a}$ infecção pós-operatória mais freqüente.

- Infecções altas: traqueobronquites;

- Pneumonia: elevada mortalidade; dor, febre alta, alterações radiológicas.

- Abscesso pulmonar e empiema pleural.

- Coleção purulenta no pulmão ou cavidade Pleural;

- Quadro grave, elevada mortalidade.

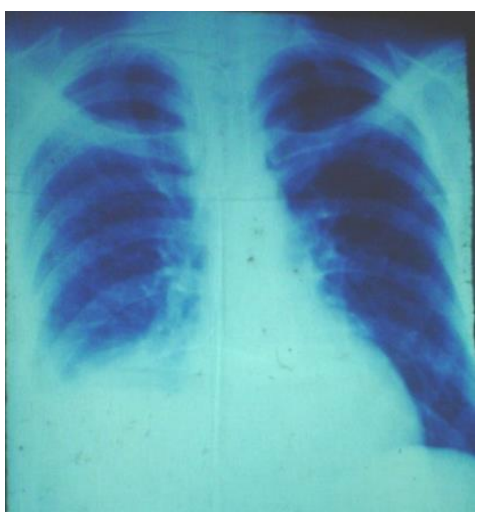

Pneumonia + derrame pleural à direita póscolecistectomia

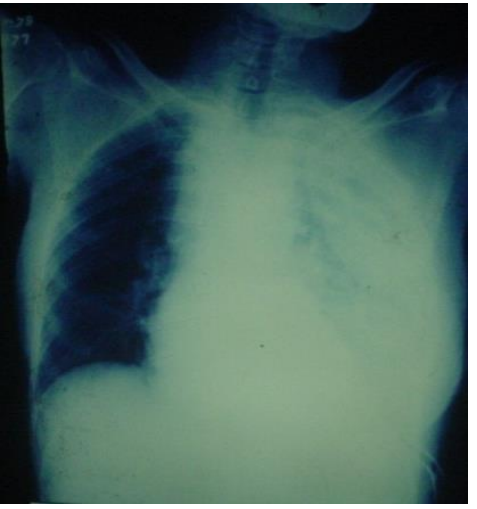

Empiema pleural à direita

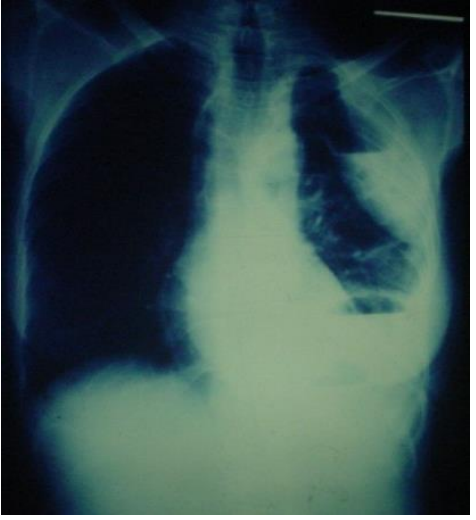

Abscessos da cavidade pleural após operação de Heller 


\section{FATORES DE RISCO DE INFECÇÃO EM CIRURGIA ${ }^{8-11}$}

\section{Fatores bacterianos:}

- Número de bactérias: acima de $10^{5}$ por grama de tecido

- Contaminação endógena

- Atentar para infecções à distância

- Gram negativas: lipopolissacarídeos da parede bacteriana (endotoxinas)

- Aeróbicas produzem mais infecções de ferida e infecção respiratória

\section{Fatores relacionados ao paciente}

- Idade (crianças e idosos)

- Diabetes mellito (alta susceptibilidade)

- Imunossupressão

- Múltiplas co-morbidades

- Tabagismo

- Obesidade (déficit na vascularização dos tecidos, hematomas, espaço morto, duração das operações)

- Câncer (inibição da função celular, linfócitos, fagocitose)

- Desnutrição

- Doenças associadas (infecciosas ou não)

- Internação pré-operatória (quanto maior o tempo, mais infecção)

\section{Relacionados à técnica cirúrgica}

- Duração das operações - cada hora adicional duplica a probabilidade de haver infecção

- Operações de emergência (alto risco)

- Considerar: risco cirúrgico, potencial de contaminação, duração, perda sanguínea, perfuração de vísceras, baixa imunidade, etc);

- Ambiente cirúrgico

- Ambiente de enfermarias

- Banho pré-operatório

- Tricotomia (sempre realizada imediatamente antes do ato operatório) $)^{12}$

- Preparo da pele

- Soluções degermantes de PVPI e clorexidina ${ }^{11}$

- Preparo do instetino na cirurgia digestiva ${ }^{14}$,

- Uso de drenos

- Sistemas fechados (vácuo),

- nunca pela incisão, curta duração.

- Próteses

- Baixam as defesas; só em operações limpas; assepsia rigorosa

- Ferida local 
- Presença de hematoma/seroma, necrose, fios de sutura, corpos estranhos

Com base nos fatores de risco, a CClH deve atuar na prevenção e controle da infecção hospitalar nos seguintes campos de atuação: ${ }^{13}$

1. Diagnóstico preciso dos casos de infecção. $O$ ponto fundamental de qualquer programa de controle de infecção hospitalar está na aquisição de dados de maneira correta. É preciso que tenha uma noção exata do problema para poder combatê-lo. A metodologia utilizada consta de: preenchimento obrigatório da ficha de notificação, sistema de busca ativa dos casos de infecção, ambulatório de egressos controlado pela $\mathrm{CCIH}$ e identificação dos fatores de risco da instituição.

2. Higiene corporal. Os pacientes, ainda no ambulatório, são orientados a tomar banho completo e realizar limpezas de áreas críticas do corpo. $\mathrm{Na}$ enfermaria os pacientes são novamente banhados (sabão neutro) com especial atenção na cabeça e no local da incisão cirúrgica cerca de duas horas antes da cirurgia.

3. Controle das afecções associadas: A presença de infecção comunitária aumenta em 2-3 vezes o risco de se contrair infecção hospitalar. Cerca de 15\% dos pacientes apresentam infecção comunitária ${ }^{3}$. Deste modo, sempre que possível devem ser suspensas as cirurgias eletivas quando da identificação de infecções comunitárias.

4. Internamento pré-operatório mínimo: $O$ internamento pré-operatório prolongado aumenta o risco de infecção. Deve-se internar o paciente no dia da cirurgia, sempre que possível.

5. Cuidados com tricotomia: Foi verificado que a tricotomia pode modificar a microbiota do campo operatório. Há um aumento do índice de infecção de ferida quando a tricotomia é realizada com mais de 24 horas. A tricotomia deve ser feita no máximo uma hora antes da cirurgia e apenas no local da incisão, o suficiente para a colocação de curativo oclusivo ${ }^{12}$.

7. Técnica cirúrgica adequada e delicada: Segundo o Center for Disease Control (CDC), desde que a maioria das infecções pós-cirúrgicas são adquiridas na sala de operações, boa técnica é crucial para a sua prevenção e a maioria das medidas deve ser dirigida para influenciar adequadamente as equipes cirúrgicas ${ }^{13}$. Cirurgias com duração acima de três horas aumentam o risco de infecção de 3-4 vezes; que o uso excessivo do bisturi elétrico e a utilização de drenos laminares aumentam em duas vezes a infecção. Além disso, manusear os tecidos delicadamente, evitar sangramentos e a formação 
de hematomas, erradicar espaço morto, tecido desvitalizado e corpo estranho são essenciais na prevenção da infecção de ferida ${ }^{10}$.

\section{Divulgação dos resultados da $\mathbf{C C I H}$ e da relação infecção/cirurgião: $\mathrm{O}$} trabalho de qualquer Comissão de Controle de Infecção se baseia essencialmente em um sistema de vigilância epidemiológica e educação da comunidade hospitalar. A divulgação dos resultados faz com que a comunidade hospitalar tenha um retorno de suas ações no intuito de combater a infecção hospitalar. Divulgação de taxas de infecção segmentadas, nos diferentes setores do hospital determina um aumento do compromisso de cada funcionário em sua redução. Desde que a técnica cirúrgica é ponto fundamental na gênese da maioria das infecções de ferida em cirurgias limpas, grande ênfase deve ser dada à educação das equipes cirúrgicas ${ }^{6,13}$.

9. Rigoroso controle na prescrição de antimicrobianos: $A$ utilização de antimicrobianos deve ser feita sob um controle bastante rígido, especialmente tendo em mente o grave problema da crescente resistência bacteriana aos antimicrobianos $^{16}$.

\section{ANTIBIOTICOPROFILAXIA}

A utilização do antibiótico de maneira profilática, deve ser feita em dose única, com cefalosporinas de 1aㅡ geração (cefazolina), na indução anestésica, ou no máximo 60 minutos antes da realização da incisão cirúrgica. Caso o procedimento cirúrgico se prolongue por mais de três horas uma nova dose deve ser injetada, mas o antibiótico é suspenso ao término da cirurgia ${ }^{14}$.

O padrão de resistência bacteriana encontrado em alguns hospitais tem assustado especialistas no assunto ${ }^{15}$. Entre as causas apontadas como responsáveis por este fenômeno, encontram-se o uso indiscriminado de antibióticos dentro e fora de hospitais, auto-medicação, uso abusivo na agricultura e veterinária ${ }^{16}$. A padronização da utilização profilática de antibióticos utilizando drogas de primeira linha (cefazolina), em dose única ou enquanto dure a cirurgia e em cirurgias contaminadas deve estar claramente estabelecida. Nas cirurgias contaminadas deve ser utilizada a antibioticoterapaia apenas durante o procedimento, obedecendo à meia-vida do fármaco utilizado. Dependendo da microbiota esperada, pode-se associar metronidazol, e em algumas situações pode ser mudado o esquema de profilaxia para cefoxitina (cirurgia de cólon) ${ }^{14-18}$. 


\section{DEFINIÇÕES}

Septicemia: Pode ocorrer no pós-operatório por algumas das causas de infecção cirúrgica. Caracteriza-se por mais de dois picos febris em 24 horas, hipotensão e oligúria. - A síndrome da resposta inflamatória sistêmica (SRIS) à infecção passa por graus sucessivos de acordo com a gravidade da septicemia.

Síndrome da resposta inflamatória sistêmica (SRIS) na vigência de sepse: Paciente com temperatura $>38^{\circ} \mathrm{C}$ ou $<36^{\circ} \mathrm{C}$ - Freqüência cardíaca $>90 \mathrm{bpm}$ Freqüência respiratória $>20$ movimentos/ minuto - Glóbulos brancos $>12.000$ ou $<4.000$.

Sepse: É atualmente definida como uma "disfunção de órgãos com risco de vida causada por uma resposta desregulada do hospedeiro à infecção ".

Sepse grave: Sepse + disfunção orgânica, anormalidades da hipoperfusão (acidose, alteração do estado mental) ou hipotensão.

Choque séptico: Sepse + anormalidades da hipoperfusão + hipotensão apesar da reposição de volume.

Infecção intra-abdominal: Conhecida como sepse intra-abdominal, apresentase como peritonite bacteriana difusa ou abscesso intra-abdominal, habitualmente causada por perfuração traumática ou inflamatória das vísceras, deiscências de suturas, obstruções ou isquemias intestinais, inflamação e infecção de útero e anexos (trompa e ovário). Além das medidas de suporte (hidratação, antibioticoterapia de largo espectro), são necessárias intervenções cirúrgicas para desbridamento, lavagem da cavidade abdominal, remoção da causa infecciosa e drenagem de abscessos intraperitoneais ${ }^{17,18}$.

\section{REFERÊNCIAS}

1. Klevens RM, Edwards JR, Richards CL Jr, et al. Estimating health careassociated infections and deaths in U.S. hospitals, 2002. Public Health Rep. 2007;122(2):160-6.

2. Owens CD, Stoessel K. Surgical site infections: epidemiology, microbiology and prevention. J Hosp Infect. 2008;70(Suppl 2): 3-10.

3. Stein GE. Antimicrobial resistance in the hospital setting: impact, trends, and infection control measures. Pharmacotherapy. 2005;25 (10 Pt 2):44S-54S.

4. Broex ECJ, van Asselt ADI, Bruggeman CA, van Tiel FH. Surgical site infections: how high are the costs? J Hosp Infect. 2009;72(3):193- 201. 
5. Surgical Site Infections (SSI). Atlanta, GA: Centers for Disease Control and Prevention [updated December 18, 2008; cited Nov 1, 2009]. Available at www.cdc.gov=ncidod $=$ dhqp $=F A Q \_S S I . h t m l$.

6. Ferraz EM. Manual de Controle de Infecção em Cirurgia do Colégio Brasileiro de Cirurgiões, São Paulo, Editora Pedagógica Universitária Ltda, 1982.

7. Tanner J, Swarbrook S, Stuart J. Surgical hand antisepsis to reduce surgical site infection. Cochrane Database Syst Rev. 2008;(1): CD004288.

8. Kirby JP, Mazuski JE. Prevention of surgical site infection. Surg Clin North Am. 2009;89(2):365-89.

9. Dominioni L, Imperatori A, Rotolo N, Rovera F. Risk factors for surgical infections. Surg Infect (Larchmt). 2006;7(Suppl 2):S9-S12 23.

10. Anderson DJ, Kaye KS, Classen D, et al. Strategies to prevent surgical site infections in acute care hospitals. Infect Control Hosp Epidemiol. 2008;29(Suppl 1):S51-S61.

11. Darouiche RO, Wall MJ Jr, Itani KM, et al. Chlorhexidine-alcohol versus povidone-iodine for surgical-site antisepsis. $N$ Engl $J$ Med. 2010;362(1):18-26.

12. Tanner J, Woodings $\mathrm{D}$, Moncaster K. Preoperative hair removal to reduce surgical site infection. Cochrane Database Syst Ver. 2006.

13. Berríos-Torres SI. Evidence-Based Update to the U.S. Centers for Disease Control and Prevention and Healthcare Infection Control Practices Advisory Committee Guideline for the Prevention of Surgical Site Infection: Developmental Process. Surg Infect (Larchmt). 2016;17(2):256-61.

14. Nichols RL, Holmes JW. Prophylaxis in bowel surgery. Curr Clin Top Infect Dis. 1995;15:76-96.

15. Anderson DJ, Sexton, DJ, Kanafani ZA, et al. Severe surgical site infection in community hospitals: Epidemiology, key procedures, and the changing prevalence of methicillinresistant Staphylococcus aureus. Infect Control Hosp Epidemiol. 2007;28:1047-53.

16. Engemann JJ, Carmeli Y, Cosgrove SE, et al. Adverse clinical and economic outcomes attributable to methicillin resistance among patients with Staphylococcus aureus surgical site infection. Clin Infect Dis. 2003;36:592-8.

17. Golan Y. Empiric therapy for hospital-acquired, Gram-negative complicated intra-abdominal infection and complicated urinary tract infections: a systematic literature review of current and emerging treatment options. BMC Infect Dis. 2015;15:313.

18. Kurup A, Liau KH, Ren J, Lu MC, Navarro NS, Farooka MW, Usman N, Destura RV, Sirichindakul B, Tantawichien T, Lee CK, Solomkin JS. Antibiotic management of complicated intra-abdominal infections in adults: The Asian perspective. Ann Med Surg (Lond). 2014;3(3):85-91. 